\title{
Исследование характеристик гетеропереходных солнечных элементов на основе тонких пластин монокристаллического кремния
}

\author{
(С) Е.И. Теруков ${ }^{1,2}$, А.С. Абрамов ${ }^{2}$, Д.А. Андроников ${ }^{2}$, К.В. Емцев ${ }^{2}$, \\ И.Е. Панайотти ${ }^{1}$, А.С. Титов ${ }^{1,2}$, Г.Г. Шелопин ${ }^{2}$ \\ ${ }^{1}$ Физико-технический институт им. А.Ф. Иоффе Российской академии наук, \\ 194021 Санкт-Петербург, Россия \\ ${ }^{2}$ ООО „НТЦ тонкопленочных технологий в энергетике“, \\ 194064 Санкт-Петербург, Россия \\ E-mail: eug.terukov@mail.ioffe.ru; panaiotti@mail.ioffe.ru
}

(Получена 30 ноября 2017 г. Принята к печати 11 декабря 2017 г.)

\begin{abstract}
Проведено экспериментальное исследование рабочих характеристик гетеропереходных солнечных элементов на основе пластин монокристаллического кремния уменьшенной толщины. Установлено, что при уменьшении толщины кремниевых пластин на 40\% по сравнению со стандартными значениями происходит ухудшение эффективности фотоэлектрического преобразования до 5\%. Полученные результаты имеют практическую ценность для оценки коммерческой целесообразности производства солнечных элементов уменьшенной толщины.
\end{abstract}

DOI: $10.21883 /$ FTP.2018.07.46054.8781

\section{1. Введение}

Эффективное использование современных фотоэлектрических преобразователей (ФЭП) в качестве альтернативных источников энергии требует обеспечения экономически выгодной цены их производства. На сегодняшний день интенсивное развитие фотоэнергетики сдерживается высокой стоимостью основного материала для солнечных элементов (СЭ) - высокочистого кристаллического кремния. Постоянно растущая потребность в дорогом исходном сырье тормозит наращивание объемов выпуска кремниевых солнечных батарей и препятствует удешевлению их производства.

Гетеропереходные тонкопленочные СЭ - HIT (Heterojunction with Intrinsic Thin-layer solar cells) элементы признаны одними из наиболее перспективных ФЭП. Суть технологии их производства заключается в формировании гетеропереходов на поверхностях монокристаллических кремниевых $c$-Si пластин путем нанесения тонких пленок аморфного кремния $a$-Si:H различного типа. НІТ-элементы обладают рядом преимуществ, В частности, они могут быть полностью изготовлены в условиях низких температур (около $200^{\circ} \mathrm{C}$ ). При этом эффективность фотоэлектрического преобразования лучших образцов НІТ-элементов достаточно велика и превышает 25\% в условиях AM1.5G [1].

Задача удешевления „солнечной“ электроэнергии может быть решена путем перехода к производству НІТ-элементов на основе пластин меньшей по сравнению со стандартом толщины, что позволит экономить дорогостоящий высокочистый кремний.

Цель работы заключается в изучении характеристик фотоэлектрического преобразования НІТ-элементов, изготовленных на тонких монокристаллических кремниевых пластинах, и оценке целесообразности их коммерческого производства.

\section{2. Описание опытных образцов и условия проведения экспериментальных исследований НIT-элементов}

В работе были исследованы образцы НІТ-элементов, изготовленные в НТЦ тонкопленочных технологий в энергетике при ФТИ им. А.Ф. Иоффе. Опытные структуры (рис. 1) имели монокристаллические кремниевые подложки $n$-типа с концентрацией доноров $N_{d} \approx 10^{15} \mathrm{~cm}^{-3}$ и объемным временем жизни носителей заряда $\tau \approx 1.5$ мс. Для исследования были выбраны квадратные пластины $c$-Si площадью $243.36 \mathrm{~cm}^{2}$ стан-

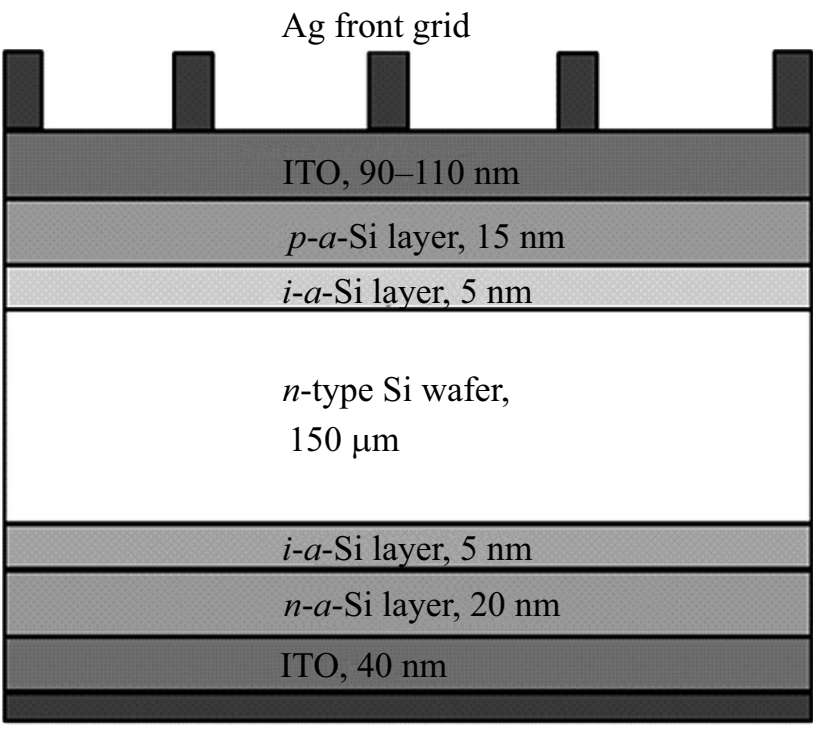

$\mathrm{Ag}, 300 \mathrm{~nm}$

Рис. 1. Схематическое изображение НІТ-элемента. 


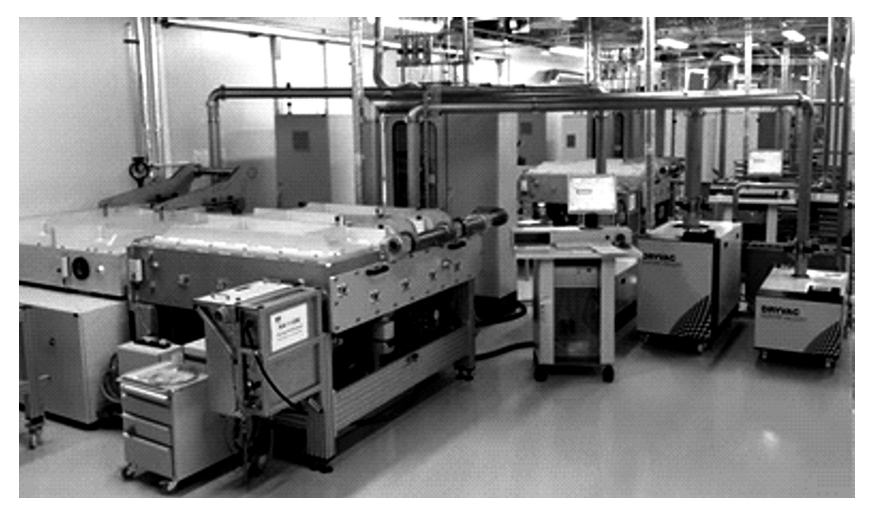

Рис. 2. Опытная производственная линия в НТЦ тонкопленочных технологий в энергетике, в состав которой входят два реактора Gen5 KAI PECVD, разработанные компанией TEL Solar.



Рис. 3. НІТ-элемент, изготовленный на тонкой пластине.

дартной $(d=150$ мкм $)$ и уменьшенной $(d=90$ мкм $)$ толщины. С целью улучшения условий поглощения света в объеме полупроводника на обеих поверхностях подложки были сформированы микротекстуры в виде случайным образом расположенных вертикальных пирамид с характерными размерами в несколько микрон. Осаждения слоев аморфного гидрогенизированного кремния проводились в реакторах Gen5 KAI PECVD с использованием газов $\mathrm{SiH}_{4}, \mathrm{H}_{2}, \mathrm{~B}\left(\mathrm{CH}_{3}\right)_{3}$ и $\mathrm{PH}_{3}$ при температуре около $200^{\circ} \mathrm{C}$ (рис. 2). В качестве дополнительного антиотражающего покрытия были нанесены прозрачные проводящие пленки оксида индия и оксида олова (ITO). При изготовлении внешних проводящих контактов применялась серебросодержащая низкотемпературная паста. На фронтальной поверхности контактная сетка типа BBL-SW была сформирована методом трафаретной печати.
Стоит отметить, что НІТ-элементы, изготовленные на тонких пластинах, обладают повышенной гибкостью (рис. 3).

Исследования вольт-амперных характеристик (BAX) опытных образцов проводились с помощью импульсного имитатора солнечного излучения Pasan Spot ${ }^{\mathrm{LIGTH}}$ Highcap с системой контактирования Grid ${ }^{\mathrm{TOUCH}}$ [2], разработанной компанией Pasan для измерения солнечных ячеек, выполненных по безбасбарной технологии. Световые (нагрузочные) ВАХ НІТ-элементов измерялись в условиях AM1.5G (1000 Вт/м²). Экспериментальные результаты представлены на рис. 4.

С целью более детального изучения характеристик опытных образцов были измерены их спектральные отклики (рис. 5). Для проведения эксперимента была использована система измерения спектрального отклика для солнечных ячеек PV Measurements Model QEX10 (пределы по длине волны испускаемого света - от 300 до 1100 нм с погрешностью \pm 2 нм).

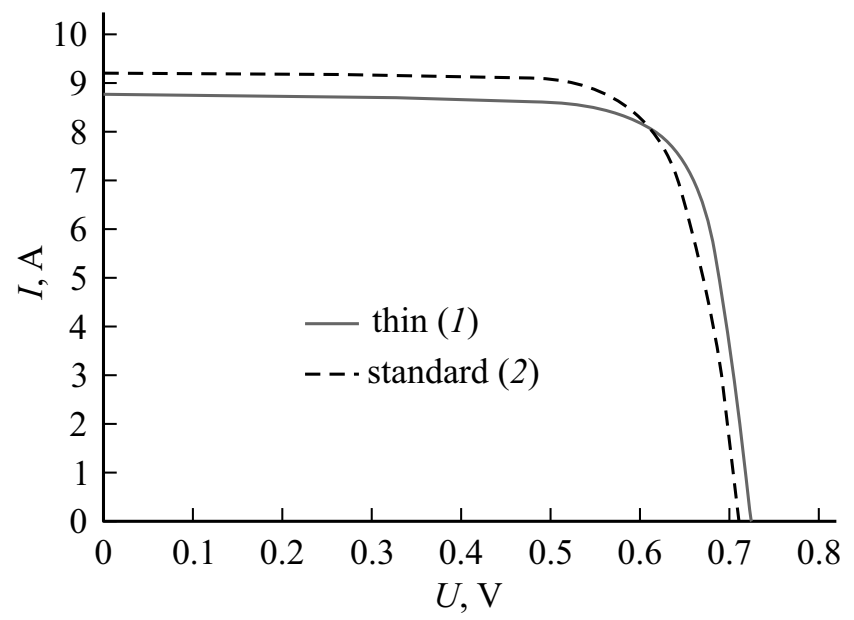

Рис. 4. Вольт-амперные характеристики НІТ-элементов уменьшенной и стандартной толщины: $d=90$ (1), 150 мкм (2).

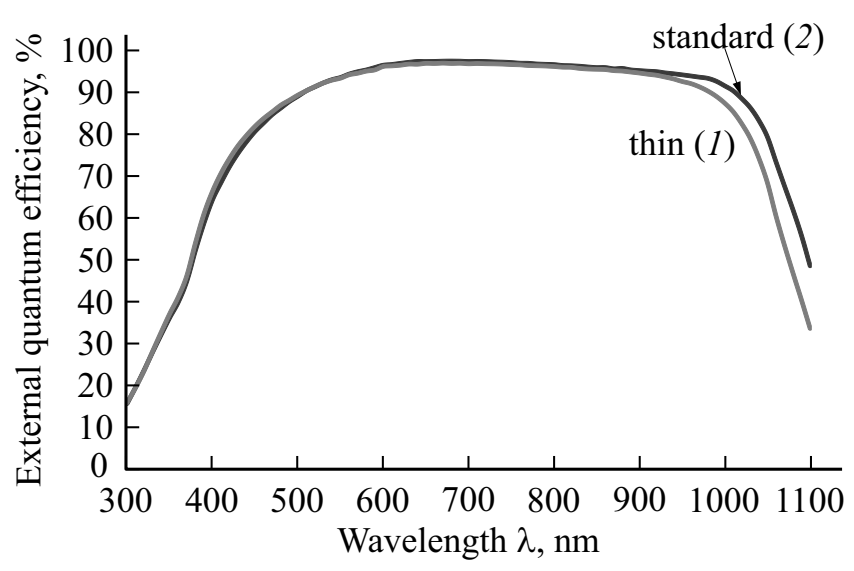

Рис. 5. Спектральные отклики НІТ-элементов уменьшенной и стандартной толщины: $d=90(1), 150$ мкм (2). 
Параметры НІТ-элементов

\begin{tabular}{c|c|c|c|c|c|c|c}
\hline$d$, МКм & $I_{\mathrm{SC}}, \mathrm{A}$ & $U_{\mathrm{OC}}, \mathrm{B}$ & $P_{m}, \mathrm{BT}$ & $U_{m}, \mathrm{~B}$ & $I_{m}, \mathrm{~A}$ & $F F, \%$ & $\eta, \%$ \\
\hline 90 & 8.814 & 0.725 & 4.971 & 0.6094 & 8.157 & 77.81 & 20.78 \\
150 & 9.267 & 0.714 & 5.029 & 0.5923 & 8.491 & 76.00 & 21.02
\end{tabular}

\section{3. Обсуждение экспериментальных результатов и выводы}

Уменьшение толщины подложки НІТ-элемента на $40 \%$ приводит к ухудшению эффективности фотоэлектрического преобразования $\eta$ на $1.5 \%$ (отн.\%) и снижению максимальной мощности СЭ $P_{m}=I_{m} \cdot U_{m}$, на $1 \%$ (отн.\%) (см. таблицу). Одновременно происходит улучшение фактора формы $F F$ более чем на $1 \%$ (отн.\%).

Результаты измерения ВАХ образцов НІТ-элементов свидетельствуют о весьма слабой зависимости величины тока короткого замыкания $I_{\mathrm{SC}}$ от толщины кремниевой подложки $d$. Значения $I_{\mathrm{SC}}$ определяются фотогенерационными процессами, об особенностях которых можно судить по виду спектрального отклика СЭ. В кристаллическом кремнии коэффициент поглощения света быстро возрастает с увеличением энергии фотонов $h v$. Так, при $h v \approx 2.5$ эВ он составляет примерно $10^{4} \mathrm{~cm}^{-1}$, а при $h v \approx 3.5$ эВ - уже превышает $10^{6} \mathrm{~cm}^{-1}$ [3]. Таким образом, спектральный отклик в основном формируется процессами поглощения коротковолновых фотонов вблизи фронтального гетероперехода HIT-элемента. Именно поэтому в широком диапазоне длин волн $\lambda \sim 300-900$ нм экспериментальные кривые на рис. 5 практически совпадают. Наблюдаемое снижение спектрального отклика до $16 \%$ при $\lambda<500$ нм, очевидно, вызвано значительными рекомбинационными потерями в слоях аморфного кремния у лицевой поверхности СЭ.

Вид спектральной характеристики в интервале $\lambda \sim 900-1100$ нм обусловлен резким ухудшением поглощения света в кристаллическом кремнии с ростом длины волны (коэффициент поглощения падает вплоть до значений менее $10^{-2} \mathrm{~cm}^{-1}$ ) [3]. Следовательно, в объеме подложки вдали от лицевой поверхности генерация носителей заряда в основном происходит за счет поглощения низкочастотных фотонов. Число таких поглощений тем больше, чем толще кремниевая пластина, на основе которой изготовлен СЭ. Поэтому у тонких HIT-элементов снижен ток короткого замыкания и наблюдается некоторое ослабление спектрального отклика в длинноволновой области (рис. 5). Однако, поскольку фотогенерация носителей заряда происходит преимущественно вблизи лицевой поверхности СЭ, уменьшение толщины пластины на $40 \%$ вызывает падение тока короткого замыкания менее чем на $5 \%$. Примерно на такую же величину снижаются и токи во внешней цепи СЭ.
По сравнению с образцами стандартной толщины напряжение $U_{m}$ и напряжение холостого хода у HIT-элементов, изготовленных на тонких пластинах $(d=90$ нм $)$, оказываются несколько выше. Плотность тока во внешней цепи исследованных СЭ зависит от соотношения темпов фотогенерации и рекомбинации в объеме и на поверхностях подложки [4]:

$$
J(U)=J_{\mathrm{SC}}-\Delta p(U)(d / \tau+S),
$$

где $U$ - падение напряжения на фронтальном гетеропереходе, $J_{\mathrm{SC}}$ - плотность тока короткого замыкания; $S-$ суммарная скорость рекомбинации на поверхностях подложки, а $\Delta p(U)$ - концентрация избыточных носителей заряда в подложке, которая нелинейно увеличивается с ростом $U$. Таким образом, при неизменных значениях $J_{\mathrm{SC}}, J(U)$ и $S$ уменьшению толщины пластины $d$ будут соответствовать повышенные значения напряжения $U$. Если $J(U)=0$, то

$$
J_{\mathrm{SC}}=\Delta p\left(U_{\mathrm{OC}}\right)(d / \tau+S),
$$

где $U_{\mathrm{OC}}-$ напряжение холостого хода. Точные значения скорости поверхностной рекомбинации в исследуемых образцах неизвестны. Однако, как показали измерения, соотношение параметров в этой зависимости таково, что при уменьшении $d$ на $40 \%$ и $J_{\mathrm{SC}}(U)$ на $5 \% U_{\mathrm{OC}}$ вырастает на $1.5 \%$. Следует ожидать, что снижение поверхностных рекомбинационных потерь позволит еще больше повысить значение напряжения холостого хода и улучшить эффективность фотоэлектрического преобразования тонких НIT-элементов.

\section{4. Заключение}

Результаты проведенного исследования показали, что ухудшение рабочих характеристик НІТ-элементов, изготовленных на пластинах с уменьшенной на $40 \%$ толщиной, не является критичным. Улучшение технологии производства таких ФЭП в перспективе может значительно повысить их эффективность. Поэтому необходимо продолжать научные разработки в направлении создания коммерчески выгодных тонких НІТ-элементов.

\section{Список литературы}

[1] K. Masuko, M. Shigematsu, T. Hashiguchi et al. IEEE J. Photovolt., 4 (6), 1433 (2014).

[2] N. Bassi, C. Clerc, Y. Pelet et al. Proc. 29th Eur. Photovoltaic Solar Energy Conf., I, 1180 (2014).

[3] T. Tiedje, E. Yablonovitch, G.D. Cody, B.G. Brooks. IEEE Trans. Electron Dev., ED-31 (5), (1984).

[4] А.В. Саченко, Ю.В. Крюченко, В.П. Костылев, И.О. Соколовский, А.С. Абрамов, А.В. Бобыль, И.Е. Понайотти, Е.И. Теруков. ФТП, 50 (2), 259 (2016).

Редактор А.Н. Смирнов 


\title{
Investigation of the characteristics \\ of heterojunction solar cells based on thin monocrystalline silicon wafers
}

E.I. Terukov ${ }^{1,2}$, A.S. Abramov ${ }^{2}$, D.A. Andronikov' ${ }^{2}$, K.V. Emtsev ${ }^{2}$, I.E. Panaiotti ${ }^{1}$, A.S. Titov ${ }^{\mathbf{1}, 2}$,

G.G. Shelopin ${ }^{2}$

${ }^{1}$ loffe Institute,

194021 St. Petersburg, Russia

${ }^{2}$ TFTC loffe R \& D Center, 194064 St. Petersburg, Russia

\begin{abstract}
An experimental study of the performance of heterojunction solar cells based on thin monocrystalline silicon wafers with reduced thickness has been carried out. It is found that decrease in wafer thickness by $40 \%$ compared to the standard values leads to decrease in the photoelectric conversion efficiency up to $5 \%$. The obtained results could be used for evaluating the commercial feasibility of solar cells with reduced wafer thickness production.
\end{abstract}

